\title{
Effects of platinum/taxane based chemotherapy on acute perfusion in human pelvic tumours measured by dynamic MRI
}

\author{
KJ Lankester', NJ Taylor', JJ Stirling², J Boxall', JA D’Arcy ${ }^{3}$, MO Leach ${ }^{3}$, GJS Rustin*,I and AR Padhani² \\ 'Department of Medical Oncology, Mount Vernon Hospital, Rickmansworth Rd, Northwood, Middlesex HA6 2RN, UK; ${ }^{2}$ Paul Strickland Scanner Centre, \\ Mount Vernon Hospital, Rickmansworth Rd, Northwood, Middlesex HA6 2RN, UK; ${ }^{3}$ Cancer Research UK Clinical MR Research Group, Institute of Cancer \\ Research, Royal Marsden NHS Foundation Trust, Cotswold Rd, Sutton SM2 5NG, UK
}

\begin{abstract}
Dynamic contrast enhanced MRI (DCE-MRI) is being used increasingly in clinical trials to demonstrate that vascular disruptive and antiangiogenic agents target tumour microcirculation. Significant reductions in DCE-MRI kinetic parameters are seen within 4-24 and $48 \mathrm{~h}$ of treatment with vascular disruptive and antiangiogenic agents, respectively. It is important to know whether cytotoxic agents also cause significant acute reductions in these parameters, for reliable interpretation of results. This study investigated changes in transfer constant $\left(K^{\text {trans }}\right)$ and the initial area under the gadolinium curve (IAUGC) following the first dose of chemotherapy in patients with mostly gynaecological tumours. A reproducibility analysis on 20 patients (using two scans performed on consecutive days) was used to determine the significance of DCE-MRI parameter changes $24 \mathrm{~h}$ after chemotherapy in 18 patients. In II patients who received platinum alone or with a taxane, there were no significant changes in $K^{\text {trans }}$ or IAUGC in either group or individual patient analyses. When the remaining seven patients (treated with a variety of agents including platinum and taxanes) were included ( $n=\mid 8$ ), there were also no significant changes in $K^{\text {trans }}$. Therefore, if combination therapy does show changes in DCE-MRI parameters then the effects can be attributed to antivascular therapy rather than chemotherapy.

British Journal of Cancer (2005) 93, 979-985. doi:I0.1038/sj.bjc.66028I4 www.bjcancer.com

Published online 18 October 2005

(c) 2005 Cancer Research UK
\end{abstract}

Keywords: DCE-MRI; vascular disruptive agents; cytotoxic; $K^{\text {trans, }}$ tumour

Tumour vasculature is a new promising target for targeted anticancer therapies; tumour vasculature may be selectively targeted by 'vascular disruptive' agents, which cause rapid blood vessel shutdown (within minutes with subsequent tumour necrosis), or the development and subsequent stabilisation of tumour vasculature may be inhibited by 'antiangiogenic agents' (Tozer et al, 2002). Magnetic resonance imaging methods provide an attractive means of investigating vascular end points (and hence to evaluate the effectiveness of vascular disruptive and antiangiogenic agents) as they are widely available, noninvasive and involve no ionising radiation (Leach et al, 2005).

Dynamic contrast-enhanced (DCE)-MRI is the MRI method most commonly used. This involves the acquisition of a series of images over several minutes following the bolus injection of a contrast agent. Low molecular weight $(<1 \mathrm{kDa})$ gadolinium chelates are usually used as contrast agents. These are small enough to diffuse out of blood vessels into tissue extravascular, extracellular spaces (EES), inducing an increase in signal intensity on $\mathrm{T}_{1}$-weighted MR images (Padhani and Dzik-Jurasz, 2004). The curve of signal intensity change following contrast agent injection indicates the rate of uptake of contrast agent into a tissue and its subsequent washout (Leach et al, 2005). Quantitative parameters

\footnotetext{
*Correspondence: Professor GJS Rustin;

E-mail: Gordon.Rustin@whht.nhs.uk

Received 7 April 2005; revised 15 September 2005; accepted 16 September 2005; published online 18 October 2005
}

relating to tissue blood flow rate, permeability surface-area product and EES volume (all of which influence the rate and magnitude of enhancement seen) are obtained from modelling of contrast agent kinetics (Tofts and Kermode, 1991; Tofts, 1997). DCE-MRI has been used to evaluate vascular disruptive and antiangiogenic agents in both xenograft studies and human trials. Significant reductions in tumour DCE-MRI kinetic parameters are seen within 4-24h with vascular disruptive agents (Dowlati et al, 2002; Evelhoch et al, 2002; Galbraith et al, 2002b, 2003; Maxwell et al, 2002; Stevenson et al, 2003) and by $48 \mathrm{~h}$ with antiangiogenic agents (Gossmann et al, 2002; Jayson et al, 2002; Checkley et al, 2003a, b; Morgan et al, 2003).

As DCE-MRI is used in early clinical trials to confirm that vascular disruptive and antiangiogenic agents target vasculature, it is important to know whether cytotoxic agents also have acute effects on vasculature. As well as aiding in the classification of agents according to their method of action, such information would also help in planning combination therapy and interpreting DCE-MRI results of such combination therapy.

The acute effects of cytotoxic agents on DCE-MRI kinetic parameters have not previously been reported, although measurements have been performed after 1-2 cycles of treatment (Barentsz et al, 1998; Reddick et al, 1999; Wolf et al, 2003; Ah-See et al, 2004). However, at these time-points objective tumour shrinkage and pathological response may also be seen, so changes in DCE-MRI parameters may be due to a reduction in blood flow secondary to tumour cell kill rather than due to direct antivascular effects. Animal studies suggest that apart from possibly the vinca 
alkaloids, significant acute vascular disruptive effects are unlikely (Chaplin and Hill, 2002), but longer term antiangiogenic effects of chemotherapy are recognised (Miller et al, 2001).

This study investigates the acute DCE-MRI effects of conventional cytotoxic agents measured $24 \mathrm{~h}$ after the start of the first cycle of treatment. Most patients had gynaecological cancers with pelvic or abdominal masses. All chemotherapy regimens included a taxane and/or platinum agent, as these are being used in combination therapy in current/future clinical trials. Taxanes exert their cytotoxic effects by inhibiting spindle formation but act by stabilising microtubules rather than inducing depolymerisation, so do not have acute vascular disruptive properties (Jordan et al, 1998; Wang et al, 2000). Platinums are alkylating agents that bind to DNA, inducing crosslink formation (Cavalli et al, 2000). Belotti et al (1996) found that both cisplatin and paclitaxel have antiangiogenic effects in vitro, but only paclitaxel had antiangiogenic effects in vivo.

\section{MATERIALS AND METHODS}

Local ethics committee approval for the trial protocol and written informed consent from all participating patients was obtained. Eligibility criteria for the study were: histologically confirmed cancer at an anatomical site suitable for imaging with MRI; tumour mass $\geqslant 3 \mathrm{~cm}$ in diameter; patient due to start first cycle of taxane or platinum-based chemotherapy regimen; calculated creatinine clearance $>50 \mathrm{ml} \mathrm{min}^{-1}$; WHO performance status $\leqslant 2$; age $\geqslant 18$ years; no history of allergic reaction to contrast agents.

Three DCE-MRI scans were performed on consecutive days: two prechemotherapy to assess the reproducibility of the technique and one 20-24h after the start of the first cycle of chemotherapy to assess response. Duration of taxane or platinum infusion varied from $1 \mathrm{~h}$ (carboplatin, docetaxel) to $6 \mathrm{~h}$ (cisplatin). Details of chemotherapy regimens used are given in Table 1.

The MRI studies were performed on a $1.5 \mathrm{~T}$, Magnetom Symphony scanner (Siemens Medical Systems, Erlangen, Germany), using a body phased array coil. In the first scanning session, initial $\mathrm{T}_{1}$ and $\mathrm{T}_{2}$-weighted anatomical images were obtained to select four suitable contiguous slices through the centre of a tumour mass. Care was taken to place the scans in the same position on the follow-up sessions in order to obtain the same anatomical slice location. This was carried out by reference to bony landmarks, by employing the same technologist for each patient visit and by confirming acceptable anatomical relocation by the study radiologist in the quality control process prior to analysis. Proton density-weighted spoiled gradient-recalled echo (GRE) images were acquired first (echo time TE $4.7 \mathrm{~ms}$, repetition time TR $350 \mathrm{~ms}$, flip angle $6^{\circ}$, slice thickness $8 \mathrm{~mm}$, four slices). Then an interleaved dynamic series of $40 \mathrm{~T}_{1}$-weighted GRE images were acquired (TE $4.7 \mathrm{~ms}$, TR $11 \mathrm{~ms}$, flip angle $35^{\circ}$, slice thickness $8 \mathrm{~mm}$, four slices, and total imaging time $8 \mathrm{~min} 5 \mathrm{~s}$ ) at the same slice positions. The contrast agent, gadopentetate dimeglumine (Gd-DTPA, Magnevist ${ }^{\circledR}$, Schering Health Care Ltd, Burgess Hill, UK), was injected intravenously using a power injector (dose $0.1 \mathrm{mmol} \mathrm{kg}{ }^{-1}$ bodyweight) at $4 \mathrm{ml} \mathrm{s}^{-1}$ during the fifth acquisition. System gain and scaling factors were maintained between acquisition of the proton density and $\mathrm{T}_{1}$-weighted dynamic series of images to enable the calculation of tissue contrast agent concentration (Parker et al, 1997).

Images were transferred to a Sun Ultra 60 workstation (Sun Microsystems, Mountain View, CA, USA) and analysed using specialist software (Magnetic Resonance Imaging Workbench (MRIW), Institute of Cancer Research, London UK) (Parker et al, 1998). Using information from anatomical and postcontrast $\mathrm{T}_{1}$ images, regions of interest (ROIs) were carefully drawn around the tumour edges for each examination by a single operator who carefully excluded areas of artefacts and blood vessels. The intra- observer variability for ROI drawing for this operator has been documented to be less than 5\% (Beresford et al, 2005).

Quantitative analysis required conversion of the MRI signal intensities to $T_{1}$ relaxation rates and then to Gd-DTPA concentrations following the methods described by Parker et al (1997). These processes are carried out in the MRIW software.

Gd-DTPA concentration at time $t, C_{t}(t)$, was calculated from the tissue $T_{1}$ using the equation

$$
C_{t}(t)=\frac{\left(1 / T_{1}(t)-1 / T_{1}(0)\right)}{r_{1}}
$$

where $T_{1}(0)$ is the tissue $T_{1}$ without contrast and $r_{1}$ is the longitudinal relaxivity of protons in vivo due to Gd-DTPA (taken to be $4.5 \mathrm{~mm}^{-1} \mathrm{~s}^{-1}$ at $1.5 \mathrm{~T}$ ) (Donahue et al, 1994).

MRIW software calculates several kinetic parameters. The initial area under the Gd-DTPA concentration time curve (IAUGC - in mM s) was calculated for the first $60 \mathrm{~s}$ following arrival of contrast agent in the tumour. Then, the data were fitted to a standard compartmental model (Kety, 1960), to characterise the arterial influx of Gd-DTPA into the tumour EES and its venous efflux. Using this model, the time course of contrast agent concentration in tissue can be described by

$$
C_{t}(t)=K^{\operatorname{trans}}\left[C_{p}(t) \otimes \exp \left(-k_{\mathrm{ep}} t\right)\right]
$$

where $C_{\mathrm{p}}(t)$ is the Gd-DTPA concentration in arterial blood plasma at time $t ; K^{\text {trans }}$ is the transfer constant for transport from plasma to the tumour EES $\left(\mathrm{min}^{-1}\right), k_{\mathrm{ep}}$ is the rate constant for transport from the EES back to plasma $\left(\mathrm{min}^{-1}\right)$ and $\otimes$ denotes the convolution integral. An assumed arterial input function (AIF) was used for the modelling procedure (Weinmann et al, 1984; Tofts, 1997) as described previously (Galbraith et al, 2002a).

Values were calculated on a voxel-by-voxel basis for $K^{\text {trans }}$ Voxels that did not enhance and those enhancing voxels that failed the modelling process or had values $>5.0 \mathrm{~min}^{-1}$ were excluded from analysis. The analysis was performed on combined voxel data from all slices containing tumour, taking the median voxel value as representative of central tendency. Median rather than the mean voxel values were used as the histogram distributions of some kinetic parameters were skewed.

Data were statistically analysed using StatsDirect software (Sale, UK). The statistical analysis used to determine reproducibility has been described previously (Bland and Altman, 1996a, b; Galbraith et al, 2002a; Padhani et al, 2002). The key statistical parameters are the $95 \%$ confidence intervals for change for a group of $n$ patients and for an individual patient (the latter also known as the repeatability statistic). The $95 \%$ confidence intervals can then be used to determine whether a change in a kinetic parameter following an intervention is statistically significant or not (see below). The within-patient coefficient of variation (wCV) was also calculated. In addition, the intra-class correlation coefficient (ICC), which gives an estimate of the reliability of the measurement method, and the ratio of between-patient variance to the withinpatient variance, $\mathrm{F}$ (obtained from a one-way analysis of variance ANOVA), were obtained.

In summary, for each patient, the difference $d$ between the two pretreatment measurements of a parameter was calculated. Data were transformed using natural logarithms if the variability of $d$ was found to depend on its mean value (Bland and Altman, 1996b). The square root of the mean squared difference, $\mathrm{dsd},\left(=\sqrt{[}\left[\left(\sum d^{2}\right) /\right.\right.$ $n$ ] where $n$ is the number of patients) was then calculated. The $95 \%$ confidence interval for change for a group of $n$ patients is then equal to $\pm(1.96 \times \mathrm{dsd}) / \sqrt{ } n)$. For an individual patient, $n=1$ so the $95 \%$ confidence interval for change is equal to $\pm(1.96 \times \mathrm{dsd})$, which is also known as the repeatability statistic, $r$ (Bland and Altman, 1996a).

The within-patient standard deviation $\mathrm{wSD}=\mathrm{dsd} / \sqrt{2}$, as there are two pretreatment measurements. This is a measure of the 
Table I Patient details

\begin{tabular}{|c|c|c|c|c|c|c|c|c|}
\hline $\begin{array}{l}\text { Patient } \\
\text { number }\end{array}$ & $\begin{array}{c}\text { Age } \\
\text { (years) }\end{array}$ & Tumour type & $\begin{array}{l}\text { Tumour size } \\
\left(\mathrm{cm}^{2}\right)^{\#}\end{array}$ & $\begin{array}{l}\text { Tumour site } \\
\text { imaged }\end{array}$ & Chemotherapy regimen ${ }^{a}$ & $\begin{array}{l}\text { No. of prior } \\
\text { chemotherapy } \\
\text { regimens }\end{array}$ & Outcome & \\
\hline I & 55 & Adeno-carcinoma, ovary & 25.5 & Pelvis - LR & Carboplatin AUC $6^{\mathrm{b}}$ & I & Stable disease ${ }^{c}$ & \\
\hline 2 & 59 & Adeno-carcinoma, ovary & 41.3 & Pelvis - P & Carboplatin AUC 6 & 0 & Stable diseases ${ }^{c}$ & \\
\hline 3 & 46 & Adeno-carcinoma, ovary & 65.4 & $\begin{array}{l}\text { Anterior abdominal } \\
\text { wall }-M\end{array}$ & Carboplatin AUC 5, Paclitaxel $175 \mathrm{mg} \mathrm{m}^{-2}$ & 0 & Stable disease ${ }^{c}$ & \\
\hline 4 & 66 & Adeno-carcinoma, ovary & 25.7 & $\begin{array}{l}\text { Para-aortic lymph } \\
\text { nodes - M }\end{array}$ & Carboplatin AUC 5 & 0 & Progressive disease $^{d}$ & \\
\hline 5 & 73 & Clear cell carcinoma, ovary & 69.5 & Pelvis - LR & Carboplatin AUC 6 & 2 & Stable disease ${ }^{c}$ & \\
\hline 6 & 42 & Primary peritoneal carcinoma & 39 & Pelvis - LR & $\begin{array}{l}\text { Cisplatin } 25 \mathrm{mg} \mathrm{m}^{-2}, \text { Docetaxel } \\
60 \mathrm{mg} \mathrm{m}^{-2} \text { weekly }\end{array}$ & 5 & Stable disease ${ }^{c}$ & \\
\hline 7 & 62 & Adeno-carcinoma, ovary & 112.1 & Pelvis - LR & $\begin{array}{l}\text { Cisplatin } 60 \mathrm{mg} \mathrm{m}^{-2} \text {, Docetaxel } 40 \mathrm{mg} \mathrm{m}^{-2} \\
\text { weekly }\end{array}$ & 1 & Partial response $^{c}$ & \\
\hline 8 & 45 & Adeno-carcinoma, ovary & 86.7 & Pelvis - P & Carboplatin AUC 6 & 0 & Stable disease $^{d}$ & \\
\hline 9 & 54 & Adeno-carcinoma, ovary & 6.8 & Pelvis - LR & Carboplatin AUC 6 & 2 & Partial response ${ }^{c}$ & \\
\hline 10 & 46 & Adeno-carcinoma, ovary & 7.4 & Pelvis LR & Carboplatin AUC 6 & I & Stable disease ${ }^{c}$ & \\
\hline 11 & 67 & Primary peritoneal carcinoma & 103.4 & Pelvis - LR & Carboplatin AUC 6, Paclitaxel $175 \mathrm{mg} \mathrm{m}^{-2}$ & । & Partial response ${ }^{d}$ & \\
\hline 12 & 70 & $\begin{array}{l}\text { Mixed mullerian tumour/ } \\
\text { carcinosarcoma }\end{array}$ & 153.6 & Pelvis - P & Cisplatin $60 \mathrm{mg} \mathrm{m}^{-2}$, Doxorubicin $60 \mathrm{mg} \mathrm{m}^{-2}$ & 0 & $\begin{array}{l}\text { Not evaluable - only I } \\
\text { cycle given }\end{array}$ & \\
\hline 13 & 65 & Mixed mullerian tumour & 93.8 & Pelvis - P & Cisplatin $70 \mathrm{mg} \mathrm{m}^{-2}$, Epirubicin $70 \mathrm{mg} \mathrm{m}^{-2}$ & 0 & Partial response ${ }^{d}$ & \\
\hline 14 & 57 & Adeno-carcinoma, ovary & 66.2 & Pelvis - LR & $\begin{array}{l}\text { Docetaxel } 80 \mathrm{mg} \mathrm{m}^{-2} \text { day I, Gemcitabine } \\
1250 \mathrm{mg} \mathrm{m}^{-2} \text { days I \& } 8\end{array}$ & 2 & Partial response ${ }^{c}$ & 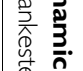 \\
\hline 15 & 49 & Granulosa cell tumour, ovary & 45.5 & Pelvis - P & $\begin{array}{l}\text { Bleomycin } 30 \mathrm{mg} \text { days } 2,8,15 \text {, Etoposide } \\
165 \mathrm{mg} \mathrm{m}^{-2} \text { days I-3, Cisplatin } 50 \mathrm{mg} \mathrm{m}^{-2} \\
\text { days I \& } 2 \text {. }\end{array}$ & 0 & Partial response $^{d}$ & 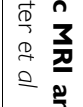 \\
\hline 16 & 59 & $\begin{array}{l}\text { Primitive neuro-ectodermal } \\
\text { tumour }\end{array}$ & 50.4 & Pelvis - P & $\begin{array}{l}\text { Cisplatin } 50 \mathrm{mg} \mathrm{m}^{-2} \text { days I\&2, Etoposide } \\
150 \mathrm{mg} \mathrm{m}^{-2} \text { days I, 2, } 3\end{array}$ & 0 & Partial response ${ }^{d}$ & ڤ̆ \\
\hline 17 & 66 & Adenocarcinoma ovary & 139.9 & Pelvis - LR & $\begin{array}{l}\text { Cisplatin } 60 \mathrm{mg} \mathrm{m}^{-2} \text { weekly, Etoposide } 50 \mathrm{mg} \\
\text { p.o. for every } 21 / 28 \text { days }\end{array}$ & 4 & $\begin{array}{l}\text { Not evaluable - only I } \\
\text { cycle given }\end{array}$ & $\sum_{\bar{\pi}}^{2}$ \\
\hline 18 & 52 & $\begin{array}{l}\text { Adenocarcinoma, } \\
\text { endometrium }\end{array}$ & 53.7 & Pelvis - P & Cisplatin $60 \mathrm{mg} \mathrm{m}^{-2}$, Doxorubicin $60 \mathrm{mg} \mathrm{m}^{-2}$ & 0 & Partial response $^{d}$ & $\begin{array}{l}0 \\
\stackrel{0}{7} \\
\substack{n \\
n}\end{array}$ \\
\hline 19 & 74 & $\begin{array}{l}\text { Poorly differentiated } \\
\text { carcinoma? Ovary? Primary } \\
\text { peritoneal carcinoma }\end{array}$ & 34.5 & $\begin{array}{l}\text { Anterior abdominal } \\
\text { wall }-M\end{array}$ & Carboplatin AUC 5 & 0 & $\begin{array}{l}\text { Not evaluable - only I } \\
\text { cycle given }\end{array}$ & 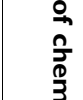 \\
\hline 20 & 29 & $\begin{array}{l}\text { Squamous cell carcinoma, } \\
\text { cervix }\end{array}$ & 4.5 & Cervix - P & $\begin{array}{l}\text { Cisplatin } 60 \mathrm{mg} \mathrm{m}^{-2} \text {, Bleomycin } 30 \mathrm{mg} \mathrm{m}^{-2} \text {, } \\
\text { Methotrexate } 300 \mathrm{mg} \mathrm{m}^{-2}\end{array}$ & 0 & $\begin{array}{l}\text { Not evaluable - had } \\
\text { surgery after I cycle }\end{array}$ & 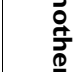 \\
\hline \multicolumn{9}{|c|}{$\begin{array}{l}\text { P.O.: orally; AUC: area under the curve; bd: twice daily. }{ }^{a} \text { Chemotherapy given intravenously and repeated every } 3 \text { weeks unless otherwise stated. LR: local recurrence; P: primary; M: metastatic disease. }{ }^{b} \text { Carboplatin dose calculated } \\
\text { according to AUC (area under the plasma concentration-time curve). }{ }^{c} \text { CA- } 125 \text { criteria. Patients I - II received platinum or taxane agents only. Patients } 19 \text { and } 20 \text { had complete data sets for days I and } 2 \text { only. }{ }^{\circ} \text { RECIST. }{ }^{\#} \text { Tumour size } \\
\text { measured on central slice. }\end{array}$} \\
\hline
\end{tabular}


precision of the measurement error. The difference between a patient's parameter measurement and the true value is expected to be less than $1.96 \times$ wSD for $95 \%$ of observations. The wCV is then obtained by dividing wSD by the group mean pretreatment value for each parameter. wCV quantifies measurement error relative to the size of the (positive) kinetic parameters. If data had to be transformed, then $\mathrm{wCV}$ was approximated by $\mathrm{wCV}=\mathrm{e}^{\mathrm{wSD}}-1$ (Bland and Altman, 1996b).

The results of the reproducibility analysis were then used to assess whether there had been a statistically significant change in kinetic parameters due to chemotherapy, either for individual patients or the group. As there were two pretreatment measurements (days 1 and 2), the mean of the two pretreatment examinations was taken as the pretreatment value for each parameter. The null hypothesis was that there would be no difference between this combined pretreatment value and the posttreatment value, that is, there would be no changes seen at $24 \mathrm{~h}$ following treatment.

For individual patients, the repeatability statistic, $r$, expressed as a percentage of the group mean pretreatment value for each parameter, gives a range within which the difference between pre- and post-treatment values would be expected to lie for $95 \%$ of observations, assuming that the null hypothesis is true. If the difference falls outside this range for a particular kinetic parameter, then a significant change was deemed to have occurred. Similarly, to assess mean response in the group, the $95 \%$ confidence interval for change, expressed as a percentage of the group mean pretreatment value, gives the range required.

\section{RESULTS}

In total, 24 female patients were imaged. The average age was 56 years old (range, 29-74 years). Data from four patients were excluded from analysis (three technical failures, one voluntary patient motion). Data from the remaining 20 patients were used for the reproducibility analysis (the two pretreatment scans). Posttreatment (day 3 ) data were available for 18 patients (data could not be obtained from all slices on day 3 for one patient due to internal organ motion and one patient was unable to complete the post-treatment scan, due to treatment toxicity). In total, 11 patients received a taxane or platinum agent only (numbers 1-11, Table 1). The remaining patients received a taxane and/or platinum based regimen, with the addition of other agents. The average time from the start of chemotherapy to the third scan was $21 \mathrm{~h}$ (range 17-23 h). Whole-group analysis regardless of the chemotherapy used was performed; those patients who received taxane or platinum chemotherapy $(n=11)$ were also analysed separately for antivascular effects.

Table 1 shows patient details including diagnosis, tumour area (taken from central slice), chemotherapy regimen used and response to treatment. Most tumours had both solid and cystic components. Patient order corresponds to that given in the figures (see below). Overall response was assessed after three cycles of chemotherapy either on CT or MRI imaging or by CA125 measurements (based on RECIST or CA125 criteria) (Therasse et al, 2000; Rustin, 2003).

Table 2 summarises the results of the reproducibility analysis for tumours. The individual patient repeatability for tumour $K^{\text {trans }}$ and IAUGC were -40.0 to $+66.7 \%$, and $\pm 33.7 \%$, respectively. For the whole group with day 3 data $(n=18)$, the $95 \%$ confidence intervals for change (expressed as percentage of the group mean pretreatment value) were -11.9 to $+13.6 \%$ and $\pm 8.8 \%$ for tumour $K^{\text {trans }}$ and IAUGC, respectively. For the subgroup receiving platinum/ taxane agents only, the $95 \%$ confidence intervals for change were -15.3 to $+18.1 \%$ and $\pm 12.0 \%$ for tumour $K^{\text {trans }}$ and IAUGC, respectively (NB $K^{\text {trans }}$ confidence intervals are asymmetrical due to the log transformation because the difference between the two
Table 2 Results of the reproducibility analysis

\begin{tabular}{lcc}
\hline Statistical variable & $\boldsymbol{K}^{\text {trans }}$ & IAUGC \\
\hline Mean & 0.39 & 6.36 \\
dsd & 0.26 & 1.09 \\
wCV $(\%)$ & $20.30 \%$ & $12.10 \%$ \\
$r$ & 0.51 & 2.14 \\
$r(\%)$ for individual patient & -40.0 to $+66.7 \%$ & $\pm 33.7 \%$ \\
$r(\%)$ for group $(n=\mid 1)$ & -15.3 to $+18.1 \%$ & $\pm 12.0 \%$ \\
$r(\%)$ for group $(n=\mid 8)$ & -11.9 to $+13.6 \%$ & $\pm 8.8 \%$ \\
ICC & & \\
F & 0.76 & 0.92 \\
\hline
\end{tabular}

$K^{\text {trans }}$ : transfer constant; IAUGC: initial area under the gadolinium concentration time curve; mean: group mean pretreatment value; dsd: squared root of the mean squared difference; wCV: within-patient coefficient of variation; $r$. individual patient repeatability; $r(\%)$ individual patient: repeatability as a percentage of the mean for an individual patient; $r(\%)$ group: repeatability for the group of patients $(n=11$ or 18). ICC: interclass correlation coefficient; F: ratio of between-patient variance to within-patient variance.
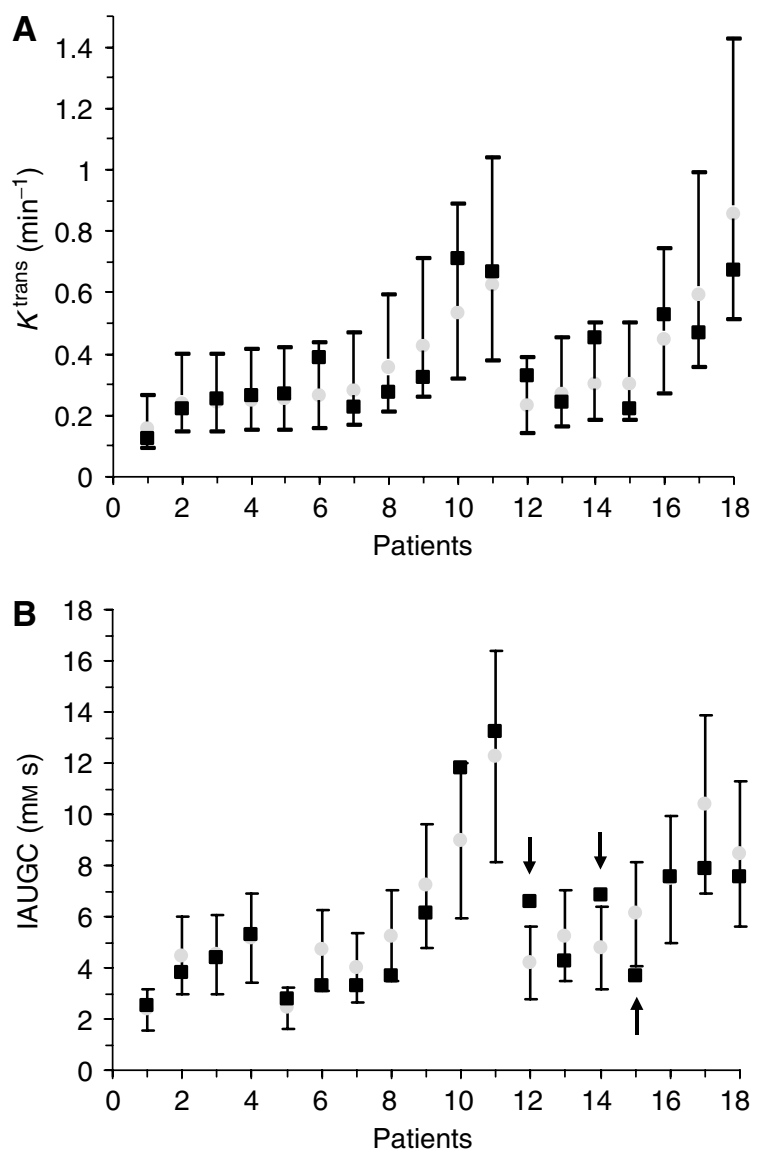

Figure I Results for individual patients. (A and B) ( $K^{\text {trans }}$ and IAUGC) Mean pretreatment (grey circle) and post-treatment values (black square) and the repeatability range for each parameter. Patients are ordered by mean pretreatment $K^{\text {trans }}$ value, demonstrating that the repeatability range is dependent on mean pretreatment value. Patient numbered $|-| \mid$ received a platinum or taxane only. The rest received a platinum or taxane plus other chemotherapy agents (see Table I).

pretreatment measures was found to depend on the mean value (Bland and Altman, 1996b)).

Figure $1 \mathrm{~A}$ and $\mathrm{B}$ show tumour pretreatment values (mean of the two pretreatment examinations), the post-treatment values and 
repeatability ranges for $K^{\text {trans }}$ and IAUGC, respectively, for each patient (patient order corresponds to Table 1). There were no significant changes post-treatment in $K^{\text {trans }}$ (Figure 1A) or in IAUGC (Figure 1B).

When data were analysed as a group $(n=11)$ for the patients who received a platinum or taxane only, again there were no significant changes in $K^{\text {trans }}$ or IAUGC. When all patients were included in the analysis $(n=18)$, there were no significant changes in individual $K^{\text {trans }}$. Two patients had significant increases (numbers 12 and 14 in Table 1: increases of 57.0 and $43.5 \%$, respectively) in IAUGC and one patient had a significant decrease (no. 15: decrease of $39.3 \%$ ). There were no significant changes in group $K^{\text {trans }}$ or IAUGC.

\section{DISCUSSION}

In this study we were very careful with patient selection to only include those who had lesions in body parts that showed little respiratory motion; this accounts for the low failure rate for our DCE-MRI examinations. This was carried out because we wanted to optimise the DCE-MRI technique and to obtain a large group of patients that received platinum and taxane-based chemotherapy. As a result, most of our patients had tumours of pelvic origin. Our patient population was therefore not typical of phase 1 clinical studies, which would ordinarily have a more heterogeneous group of patients including metastatic lung and liver lesions.

The reproducibility analysis shows that there is a wide inherent variability in individual patient repeatability for $K^{\text {trans }}$ and IAUGC. This level of reproducibility has also been found in previous studies. In a phase I study of the vascular disruptive agent, Combretastatin A-4-phosphate (CA-4-P), the individual repeatability for $K^{\text {trans }}$ was -44 to $+79 \%$ and the $95 \%$ confidence intervals for change in 16 patients was -14 to $+16 \%$ ) (Galbraith et al, 2003). Evelhoch et al also performed a reproducibility analysis as part of a phase I study of ZD6126, another vascular disruptive agent. The $w C V$ was $\pm 18 \%$ for tumour IAUGC $(n=16$, scans performed 2-6 days apart, with no treatment in the intervening period) (Evelhoch et al, 2004). From the data given in Evelhoch's et al (2004) paper, the individual patient repeatability can be calculated as $\pm 48.9 \%$ and the group $95 \%$ confidence interval for change as $\pm 11.2 \%$ for IAUGC. However, in both these trials, significant reductions in DCE-MRI kinetic parameters were still seen. The CA-4-P study was performed at our centre and the same methods used for $T_{1}$ calculation and to obtain $K^{\text {trans }}$. In the CA-4-P study, there was a group mean reduction in $K^{\text {trans }}$ of $29 \%$ for 16 patients $24 \mathrm{~h}$ following treatment with $\geqslant 52 \mathrm{mg} \mathrm{m}^{-2} \mathrm{CA}-4-\mathrm{P}$. When analysed as individuals, there were reductions in $K^{\text {trans }}$ in three patients greater than the limits set by the repeatability statistic (Galbraith et al, 2003). In the ZD6126 study, there was a significant group mean reduction in tumour IAUGC of $38.7 \%$ (nine patients, 10 tumours, measured $6 \mathrm{~h}$ after administration of $\left.56-112 \mathrm{mg} \mathrm{m}^{-2} \mathrm{ZD} 6126\right)$ and three of these patients had reductions in IAUGC greater than the limits set by the repeatability statistic (Evelhoch et al, 2004). In comparison, in our study there was no significant reduction in group $K^{\text {trans }}$ or IAUGC. Given the wide within-patient variation in $K^{\text {trans }}$ and IAUGC, it is not possible to state that the cytotoxic agents tested have no acute effects on tumour vascularity. However, based on the results from this study, one is unlikely to expect large antivascular effects in the acute setting due to cytotoxic agents alone. Therefore, if significant acute reductions in $K^{\text {trans }}$ and IAUGC seen in combination cytotoxic and antivascular therapies, one may presume they are due to the vascular disruptive agent (or a synergistic effect with the cytotoxic agent).

Chaplin and Hill (2002) compared the acute effects of CA-4-P with a number of cytotoxic agents, including cisplatin and paclitaxel, in the murine CaNT tumour. Change in functional vascular volume (measured using Hoechst 33342) at $24 \mathrm{~h}$ after drug administration was used to assess vascular disruptive activity. There was a $>80 \%$ reduction in functional vascular volume following treatment with CA-4-P, but no reduction following treatment with any of the cytotoxic agents (Chaplin and Hill, 2002). CA-4-P is classified as a tubulin depolymerising agent (Thorpe, 2004). The vinca alkaloids are also tubulin depolymerising agents, exerting their cytotoxic effects by the inhibition of spindle formation and subsequent mitotic arrest (Jordan et al, 1998). However, whereas CA-4-P induces acute blood vessel shutdown at $1 / 10$ th of the maximum tolerated dose (MTD) in an animal model (Dark et al, 1997), the vinca alkaloids only have sustained vascular disruptive effects at close to the MTD (Baguley et al, 1991; Hill et al, 1993, 1995; Chaplin et al, 1996; Sersa et al, 2001). Several cytotoxic agents do have a degree of antiangiogenic activity (based on in vitro and in vivo assays) (Miller et al, 2001) and continuous low-dose scheduling of cytotoxic agents can produce antiangiogenic effects (Browder et al, 2000; Colleoni et al, 2002; Kerbel et al, 2002). However, as there are no set criteria for defining antiangiogenic activity, it is difficult to establish its relative importance in comparison with an agent's cytotoxic action (Miller et al, 2001).

DCE-MRI, using low molecular weight contrast agents such as Gd-DTPA, is now widely available and can be incorporated into clinical trials relatively easily. $K^{\text {trans }}$ has both blood flow rate and permeability components (as Gd-DTPA is not freely diffusible) and its biological meaning is dependent on the balance between capillary permeability and blood flow in the tissue of interest (Tofts, 1997; Tofts et al, 1999). For extra-cranial tumours, the blood flow component dominates $K^{\text {trans }}$ (Tofts, 1997; Tofts et al, 1999) and the usage of $K^{\text {trans }}$ to monitor the vascular effects of drugs is now accepted. This has been validated by Maxwell et al (2002), who showed that changes in $K^{\text {trans }}$ (and IAUGC) in response to CA-4-P in a rat carcinosarcoma model matched changes in blood flow rate measured using uptake of ${ }^{125} \mathrm{I}-$ iodoantipyrine (IAP). Moreover, the pattern and time course of changes in $K^{\text {trans }}$ seen in a clinical phase I trial of CA-4-P was similar to that seen in animal models (Galbraith et al, 2003), indicating the appropriateness of using $K^{\text {trans }}$ as a surrogate marker of vascular response to treatment. This view has been endorsed by specialist panels, meeting under the auspices of Cancer Research UK (CR-UK) (Leach et al, 2005) and the US National Cancer Institute (http://imaging.cancer.gov/reportsandpublications/ ReportsandPresentations/MagneticResonance).

Two patients had small but significant increases in IAUGC. One (patient 14) went on to have a partial response to chemotherapy and the other (patient 12) was not evaluable for response (see Table 1). The IAUGC parameter cannot be simply related to tumour physiology, but it is a quantitative parameter that may be obtained without mathematical modelling. In our study, IAUGC correlated very strongly with $K^{\text {trans }}$ (Spearman's $\rho$ : 0.86, $P<0.0001$ ), confirming that it is an appropriate biomarker for antivascular effect. These increases do not fit into a pattern consistent with an antivascular effect (see above) and the cause for this effect is also uncertain, but could be related to increased blood flow. Griffon-Etienne et al (1999) reported on the use of intravital microscopy to measure red cell flux (the number of red cells passing a point per minute) and found an increase in the first few days following administration of paclitaxel or docetaxel. An increase in relative tumour blood flow rate has also been seen following cyclophosphamide and 5-fluorouracil (measured using ${ }^{86}$ Rubidium chloride extraction) (Braunschweiger, 1988; Li et al, 1991). These changes may be due to reduced blood vessel compression secondary to tumour cell kill resulting in reductions in interstitial fluid pressure (Griffon-Etienne et al, 1999).

There are uncertainties with regard to the reliability of kinetic parameter estimates derived from the application of tracer kinetic models to $\mathrm{T}_{1}$-weighted DCE-MRI data. These derive from 
assumptions implicit in kinetic models and those for the measurement of tissue contrast agent concentration. For example, the Tofts' model uses a standard description of the time varying blood concentration of contrast agent (the arterial input function), and assumes that the supply of contrast medium is not flow limited and that tissue blood volume contributes negligibly to signal intensity changes compared with that arising from contrast medium in the interstitial space. We have used a two-point technique (proton density and initial $\mathrm{T}_{1}$-weighted image) to calculate relaxation values. There are alternative schemes for calculating these values that may be more accurate. However, it should be noted that there are no head to head comparisons of such techniques. The technique that we have used has been used successfully to assess vascular response to therapy. Furthermore, international consensus meetings have recognised that this is a controversial area and have sort not to be prescriptive in this regard (Leach et al, 2005) and (http://imaging.cancer.gov/ reportsandpublications/ReportsandPresentations/MagneticResonance). It is necessary to briefly address the issue of voxels that fail the modelling process, which occurs when the Tofts' model does not fit the Gd-DTPA concentration-time curve. This occurs principally because voxels are sited over blood vessels (100\% blood volume) or are in tissues with a large blood volume. In such situations, semiquantitative parameters such as IAUGC can still be used to assess tissue enhancement and tissue response to therapy. However, as noted above, the IAUGC parameter cannot be simply related to tumour physiology; in this study, IAUGC was shown to correlated very strongly with $K^{\text {trans }}$ (see above). Interested readers are invited to review the recent article by Collins and Padhani (2004), where these issues are comprehensively discussed. Despite these complexities, it is important to remind readers that quantitative kinetic parameters can provide insights into underlying tissue patho-physiological processes and it is possible to use quantitative DCE-MRI as a tool for decision making in the clinic and pharmaceutical drug development.

In summary, within $24 \mathrm{~h}$ after taxane/platinum-based chemotherapy regimens, no significant reductions in kinetic parameters derived from $\mathrm{T}_{1}$-weighted dynamic MRI are seen. However, it is not possible to state categorically that cytotoxic agents tested have no acute effects on tumour vascularity (if they are present, then they are beyond the resolution of our technique). Nevertheless, based on the results from this study, it is unlikely to expect large antivascular effects in the acute setting due to cytotoxic agents alone. Therefore, if significant acute reductions in $K^{\text {trans }}$ and IAUGC seen in combination cytotoxic and antivascular therapies, one may presume they are due to the vascular disruptive agent. This is the first demonstration that cytotoxic agents differ from vascular disruptive agents in their effect on DCE-MRI parameters in humans, thus validates the use of DCE-MRI as a biomarker of targeting activity.

\section{ACKNOWLEDGEMENTS}

This work was supported by the Marie Curie Translational Research Trust and the Cancer Treatment and Research Trust. We thank Susan Galbraith (for writing the trial protocol and obtaining local ethics approval for the trial); Søren Bentzen and Elena Kulinskaya (for statistical advice).

\section{REFERENCES}

Ah-See M-LW, Makris A, Taylor NJ, Harrison M, Richman PI, D’Arcy JA, Burcombe RJ, Pittam MR, Ravichandran D, Stirling JJ, Leach MO, Padhani AR (2004) T1 and $\mathrm{T} 2^{*}$ weighted dynamic contrast-enhanced MRI predicts for clinico-pathological response to neoadjuvant chemotherapy in primary breast cancer. Proc ISMRM, Vol 12, 1992, Kyoto, Japan

Baguley BC, Holdaway KH, Thomsen LL, Zhuang L, Zwi L (1991) Inhibition of growth of colon 38 adenocarcinoma by vinblastine and colchicine: evidence for a vascular mechanism. Eur J Cancer 27: 482-487

Barentsz JO, Berger-Hartog O, Witjes JA, Hulsbergen-van der Kaa C, Oosterhof GO, VanderLaak JA, Kondacki H, Ruijs SH (1998) Evaluation of chemotherapy in advanced urinary bladder cancer with fast dynamic contrast-enhanced MR imaging. Radiology 207: $791-797$

Belotti D, Vergani V, Drudis T, Borsotti P, Pitelli M, Viale G, Giavazzi R, Taraboletti G (1996) The microtubule-affecting drug paclitaxel has antiangiogenic activity. Clin Cancer Res 2: 1843-1849

Beresford MJ, Ah-See M-LW, Taylor NJ, Stirling JJ, Makris A, D’Arcy JA, Leach MO, Padhani AR (2005) Inter- and intra-observer variability of DCE-MRI in breast cancer. Proc ISMRM, Miami Beach, FL, Vol 13, pp 1863

Bland J, Altman D (1996a) Measurement error [corrected and republished article originally printed in BMJ 1996 Jun 29; 312(7047):1654] [see comments]. BMJ 313: 744

Bland J, Altman D (1996b) Measurement error proportional to the mean [published erratum appears in BMJ 1996 Sep 21; 313(7059):744]. BMJ 313: 106

Braunschweiger P (1988) Effect of cyclophosphamide on the pathophysiology of RIF-1 solid tumors. Cancer Res 48: 4206-4210

Browder T, Butterfield C, Kraling B, Shi B, Marshall B, O'Reilly M, Folkman J (2000) Antiangiogenic scheduling of chemotherapy improves efficacy against experimental drug-resistant cancer. Cancer Res 60: 1878-1886

Cavalli F, Hansen HH, Kaye SB (2000) Textbook of Medical Oncology. London: Martin Dunitz Ltd

Chaplin D, Hill S (2002) The development of Combretastatin A4 phosphate as a vascular targeting agent. Int J Radiat Oncol Biol Phys 54: 1491-1496

Chaplin DJ, Pettit GR, Parkins CS, Hill SA (1996) Antivascular approaches to solid tumour therapy: evaluation of tubulin binding agents. $\mathrm{Br} J$ Cancer Suppl 27: S86-S88

Checkley D, Tessier JJ, Kendrew J, Waterton JC, Wedge SR (2003a) Use of dynamic contrast-enhanced MRI to evaluate acute treatment with ZD6474, a VEGF signalling inhibitor, in PC-3 prostate tumours. $\mathrm{Br}$ Cancer 89: $1889-1895$

Checkley D, Tessier JJ, Wedge SR, Dukes M, Kendrew J, Curry B, Middleton B, Waterton JC (2003b) Dynamic contrast-enhanced MRI of vascular changes induced by the VEGF-signalling inhibitor ZD4190 in human tumour xenografts. Magn Reson Imaging 21: 475-482

Colleoni M, Rocca A, Sandri MT, Zorzino L, Masci G, Nole F, Peruzzotti G, Robertson C, Orlando L, Cinieri S, de BF, Viale G, Goldhirsch A (2002) Low-dose oral methotrexate and cyclophosphamide in metastatic breast cancer: antitumor activity and correlation with vascular endothelial growth factor levels. Ann Oncol 13: $73-80$

Collins DJ, Padhani AR (2004) Dynamic magnetic resonance imaging of tumor perfusion. Approaches and biomedical challenges. IEEE Engl Med Biol Mag 23: $65-83$

Dark GG, Hill SA, Prise VE, Tozer GM, Pettit GR, Chaplin DJ (1997) Combretastatin A-4, an agent that displays potent and selective toxicity toward tumour vasculature. Cancer Res 57: 1829-1834

Donahue K, Burstein D, Manning W, Gray M (1994) Studies of Gd-DTPA relaxivity and proton exchange rates in tissue. Magn Reson Med 32: $66-76$

Dowlati A, Robertson K, Cooney M, Petros WP, Stratford M, Jesberger J, Rafie N, Overmoyer B, Makkar V, Stambler B, Taylor A, Waas J, Lewin JS, McCrae KR, Remick SC (2002) A phase I pharmacokinetic and translational study of the novel vascular targeting agent combretastatin a-4 phosphate on a single-dose intravenous schedule in patients with advanced cancer. Cancer Res 62: $3408-3416$

Evelhoch J, LoRusso P, DelProposto Z, Stark K, Latif Z, Morton P, Waterton J, Wheeler C, Barge A (2002) Dynamic contrast-enhanced MRI evaluation of the effects of ZD6126 on tumor vasculature in a phase I clinical trial. Proc ISMRM, Honolulu, Hawaii, Vol 10, 2095pp

Evelhoch JL, LoRusso PM, He Z, DelProposto Z, Polin L, Corbett TH, Langmuir P, Wheeler C, Stone A, Leadbetter J, Ryan AJ, Blakey DC, Waterton JC (2004) Magnetic resonance imaging measurements of the response of murine and human tumors to the vascular-targeting agent ZD6126. Clin Cancer Res 10: 3650-3657 
Galbraith S, Lodge M, Taylor N, Rustin G, Bentzen S, Stirling J, Padhani A (2002a) Reproducibility of dynamic contrast enhanced MRI in human muscle and tumours - comparison of quantitative and semi-quantitative analysis. NMR Biomed 15: $132-142$

Galbraith SM, Maxwell RJ, Lodge MA, Tozer GM, Wilson J, Taylor NJ, Stirling JJ, Sena L, Padhani AR, Rustin GJS (2003) Combretastatin A4 phosphate has tumour anti-vascular activity in rat and man as demonstrated by dynamic magnetic resonance imaging. J Clin Oncol 21: $2831-2842$

Galbraith SM, Rustin GJS, Lodge MA, Taylor NJ, Stirling JJ, Jameson M, Thompson P, Hough D, Gumbrell L, Padhani AR (2002b) Effects of 5,6dimethylxanthenone-4-acetic acid on human tumor microcirculation assessed by dynamic contrast-enhanced magnetic resonance imaging. J Clin Oncol 20: $3826-3840$

Gossmann A, Helbich TH, Kuriyama N, Ostrowitzki S, Roberts TP, Shames DM, van Bruggen N, Wendland MF, Israel MA, Brasch RC (2002) Dynamic contrast-enhanced magnetic resonance imaging as a surrogate marker of tumor response to anti-angiogenic therapy in a xenograft model of glioblastoma multiforme. J Magn Reson Imaging 15: $233-240$

Griffon-Etienne G, Boucher Y, Brekken C, Suit HD, Jain RK (1999) Taxaneinduced apoptosis decompresses blood vessels and lowers interstitial fluid pressure in solid tumors: clinical implications. Cancer Res 59: $3776-3782$

Hill SA, Lonergan SJ, Denekamp J, Chaplin DJ (1993) Vinca alkaloids: antivascular effects in a murine tumour. Eur J Cancer 29A: 1320-1324

Hill SA, Sampson LE, Chaplin DJ (1995) Anti-vascular approaches to solid tumour therapy: evaluation of vinblastine and flavone acetic acid. Int $J$ Cancer 63: 119-123

Jayson GC, Zweit J, Jackson A, Mulatero C, Julyan P, Ranson M, Broughton L, Wagstaff J, Hakannson L, Groenewegen G, Bailey J, Smith N, Hastings D, Lawrance J, Haroon H, Ward T, McGown AT, Tang M, Levitt D, Marreaud S, Lehmann FF, Herold M, Zwierzina H (2002) Molecular imaging and biological evaluation of HuMV833 anti-VEGF antibody: implications for trial design of antiangiogenic antibodies. J Natl Cancer Inst 94: $1484-1493$

Jordan A, Hadfield JA, Lawrence NJ, McGown AT (1998) Tubulin as a target for anticancer drugs: agents which interact with the mitotic spindle. Med Res Rev 18: $259-296$

Kerbel RS, Klement G, Pritchard KI, Kamen B (2002) Continuous low-dose anti-angiogenic/metronomic chemotherapy: from the research laboratory into the oncology clinic. Ann Oncol 13: 12-15

Kety S (1960) Blood-tissue exchange methods. Theory of blood-tissue exchange and its application to measurement of blood flow. Methods Med Res 8: 223-227

Leach MO, Brindle KM, Evelhoch JL, Griffiths JR, Horsman MR, Jackson A, Jayson GC, Judson IR, Knopp MV, Maxwell RJ, McIntyre D, Padhani AR, Price P, Rathbone R, Rustin GJ, Tofts PS, Tozer GM, Vennart W, Waterton JC, Williams SR, Workman P (2005) The assessment of antiangiogenic and antivascular therapies in early-stage clinical trials using magnetic resonance imaging: issues and recommendations. $\mathrm{Br} J$ Cancer 92: 1599- 1610

Li S, Wehrle J, Glickson J, Kumar N, Braunschweiger P (1991) Tumor bioenergetics and blood flow in RIF-1 murine tumors treated with 5fluorouracil. Magn Reson Med 22: 47-56

Maxwell R, Wilson J, Prise V, Vojnovic B, Rustin G, Lodge M, Tozer G (2002) Evaluation of the anti-vascular effects of combretastatin in rodent tumours by dynamic contrast enhanced MRI. NMR Biomed 15: 89-98

Miller KD, Sweeney CJ, Sledge Jr GW (2001) Redefining the target: chemotherapeutics as antiangiogenics. J Clin Oncol 19: 1195-1206

Morgan B, Thomas AL, Drevs J, Hennig J, Buchert M, Jivan A, Horsfield MA, Mross K, Ball HA, Lee L, Mietlowski W, Fuxuis S, Unger C, O’Byrne
K, Henry A, Cherryman GR, Laurent D, Dugan M, Marme D, Steward WP (2003) Dynamic contrast-enhanced magnetic resonance imaging as a biomarker for the pharmacological response of PTK787/ZK 222584, an inhibitor of the vascular endothelial growth factor receptor tyrosine kinases, in patients with advanced colorectal cancer and liver metastases: results from two phase I studies. J Clin Oncol 21: 3955-3964

Padhani AR, Dzik-Jurasz A (2004) Perfusion MR imaging of extracranial tumor angiogenesis. Top Magn Reson Imaging 15: 41-57

Padhani AR, Hayes C, Landau S, Leach MO (2002) Reproducibility of quantitative dynamic MRI of normal human tissues. NMR Biomed 15: $143-153$

Parker G, Suckling J, Tanner S, Padhani A, Husband J, Leach M (1998) MRIW: parametric analysis software for contrast-enhanced dynamic MR imaging in cancer. Radiographics 18: 497-506

Parker GJ, Suckling J, Tanner SF, Padhani AR, Revell PB, Husband JE, Leach MO (1997) Probing tumor microvascularity by measurement, analysis and display of contrast agent uptake kinetics. J Magn Reson Imaging 7: $564-574$

Reddick W, Taylor J, Fletcher B (1999) Dynamic MR imaging (DEMRI) of microcirculation in bone sarcoma. J Magn Reson Imaging 10: 277-285

Rustin GJ (2003) Use of CA-125 to assess response to new agents in ovarian cancer trials. J Clin Oncol 21: 187-193

Sersa G, Krzic M, Sentjurc M, Ivanusa T, Beravs K, Cemazar M, Auersperg M, Swartz HM (2001) Reduced tumor oxygenation by treatment with vinblastine. Cancer Res 61: 4266-4271

Stevenson JP, Rosen M, Sun W, Gallagher M, Haller DG, Vaughn D, Giantonio B, Zimmer R, Petros WP, Stratford M, Chaplin D, Young SL, Schnall M, O’Dwyer PJ (2003) Phase I trial of the antivascular agent combretastatin A4 phosphate on a 5-day schedule to patients with cancer: magnetic resonance imaging evidence for altered tumor blood flow. J Clin Oncol 21: $4428-4438$

Therasse P, Arbuck SG, Eisenhauer EA, Wanders J, Kaplan RS, Rubinstein L, Verweij J, Van Glabbeke M, van Oosterom AT, Christian MC, Gwyther SG (2000) New guidelines to evaluate the response to treatment in solid tumors. European Organization for Research and Treatment of Cancer, National Cancer Institute of the United States, National Cancer Institute of Canada. J Natl Cancer Inst 92: 205-216

Thorpe PE (2004) Vascular targeting agents as cancer therapeutics. Clin Cancer Res 10: 415-427

Tofts PS (1997) Modeling tracer kinetics in dynamic Gd-DTPA MR imaging. J Magn Reson Imaging 7: $91-101$

Tofts P, Brix G, Buckley D, Evelhoch J, Henderson E, Knopp M, Larsson H, Lee T, Mayr N, Parker G, Port R, Taylor J, Weisskoff R (1999) Estimating kinetic parameters from dynamic contrast-enhanced $\mathrm{T}(1)$-weighted MRI of a diffusable tracer: standardized quantities and symbols. J Magn Reson Imaging 10: $223-232$

Tofts PS, Kermode AG (1991) Measurement of the blood-brain barrier permeability and leakage space using dynamic MR imaging. 1. Fundamental concepts. Magn Reson Med 17: 357-367

Tozer GM, Kanthou C, Parkins CS, Hill SA (2002) The biology of the combretastatins as tumour vascular targeting agents. Int J Exp Pathol 83: $21-38$

Wang TH, Wang HS, Soong YK (2000) Paclitaxel-induced cell death: where the cell cycle and apoptosis come together. Cancer 88: 2619-2628

Weinmann HJ, Laniado M, Mutzel W (1984) Pharmacokinetics of GdDTPA/ dimeglumine after intravenous injection into healthy volunteers. Physiol Chem Phys Med NMR 16: 167-172

Wolf W, Presant C, Waluch V, Leberthon B (2003) A unique methodology using dynamic contrast enhanced MRI (DEMRI) for quantifying antiangiogenic effects (AAE) of chemotherapy: AAE of docetaxel (DOC) correlate with tumor response (TR). Proc ASCO, Chicago, 824pp 